\title{
Hamsa
}

H㓷MSA Journal of Judaic and Islamic Studies

\section{Antroponimia de los judíos de la aljama de Perpiñán (finales del s. XIV principios del s. XV)}

\section{Meritxell Blasco Orellana}

\section{(2) OpenEdition}

1 Journals

\section{Edición electrónica}

URL: https://journals.openedition.org/hamsa/657

DOI: 10.4000/hamsa.657

ISSN: 2183-2633

\section{Editor}

CIDEHUS - Centro Interdisciplinar de História Culturas e Sociedades da Universidade de Évora

\section{Referencia electrónica}

Meritxell Blasco Orellana, «Antroponimia de los judíos de la aljama de Perpiñán (finales del s. XIV principios del s. XV)», Hamsa [En línea], 3 | 2017, Publicado el 31 marzo 2017, consultado el 13 mayo 2021. URL: http://journals.openedition.org/hamsa/657 ; DOI: https://doi.org/10.4000/hamsa.657

\section{(c) (i) (9)}

Hamsa est mise à disposition selon les termes de la Licence Creative Commons Attribution - Pas d'Utilisation Commerciale - Pas de Modification 4.0 International. 


\title{
Antroponimia de los judíos de la aljama de Perpiñán (finales del s. XIV principios del s. XV)
}

\author{
Meritxell Blasco Orellana \\ Universidad de Barcelona
}

\section{Resumo:}

O objetivo deste artigo é o de contribuir com novos dados para o estudo da antroponímia dos judeus da aljama de Perpinhão em finais do séc. XIV, a partir de fragmentos dos pinqasim do leilão dos bancos da sinagoga.

Palavras-chave: Judeus de Perpinhão, antroponímia, Girona, Aragón, nomes, sobrenomes

\section{Resumen:}

El objetivo de este artículo es aportar nuevos datos para el estudio de la antroponimia de los judíos de la aljama de Perpiñán a finales del s. XIV a partir de los fragmentos de los pinqasim contables de la de la subasta de los bancos de su sinagoga.

Palabras-Ilave: Judíos de Perpiñán, antroponimia, Girona, Aragón, nombres, apellidos

\begin{abstract}
:
This article offers the onomastic study to the Jews of Perpignan at the end of the $14^{\text {th }}$ century from the fragments of the accounting pinqasim of the public auction of the banks of the Perpignan's synagogue.
\end{abstract}

Key words: Jews of Perpignan, anthroponomy, Girona, Aragón, names, surnames

\section{Antecedentes}

En el año 2000 se publicó el estudio, a cargo del Dr. José Ramón Magdalena (et alii), de los fragmentos de un interesante pinqas perteneciente a la aljama hebrea de Perpiñán ${ }^{1}$. Este cuaderno fragmentario ${ }^{2}$ formaba parte de los fondos hebraicos del Archivo Municipal de Girona procedentes de las viejas encuadernaciones de diversos protocolos notariales y códices. Este cuaderno contable contenía el registro de la subasta de los bancos de la sinagoga de la aljama de Perpiñán y, por referencias internas podemos fecharlo entre finales del s. XIV (1383) y principios del s. XV (1412). Lo más interesante de este documento es la larga lista de judíos que aparecen de dicha aljama, los bancos de la sinagoga que alquilaban y cuál era el valor de dicho alquiler.

Pasado los años, en el Archivo de la Corona de Aragón, se encontraron en la guarda posterior del Llibre de comptes de la Procuració Reial del Rosselló i la Cerdanya, Real Patrimonio,

\footnotetext{
${ }^{1}$ Véase José Ramón Magdalena Nom de Déu et alii, “A Fifteenth-Century Hebrew Manuscript from the Aljama of Perpignan", Hispania Judaica Bulletin 3 (2000/5760), p. 145-183 http://www.hum.huji.ac.il/upload/HJB3/Magdalena.pdf

2 Este lote documental consta de 9 bifolios y 13 fragmentos sueltos y en ningún lugar consta su procedencia o de dónde fueron extraídos.
} 
Maestre Racional, volumen 63 (años 1416-1417), diversos fragmentos, en papel, de documentos hebraicos que, a primera vista, acaso tuviesen alguna relación o parentesco con los hebraicos del Archivo Municipal de Girona. Efectivamente, entre los diversos fragmentos de pinqasim contables apareció un fragmento (escrito a recto y verso) que hace referencia a los usuarios judíos de algunos bancos y asientos de una sinagoga que, por las coincidencias entre la antroponimia judía de las listas del Archivo Municipal de Gerona es, sin duda, la de Perpiñán ${ }^{3}$. Podemos afirmar que ambos lotes de fragmentos pertenecieron, en su momento, al mismo fondo documental de los archivos de documentación privada de la aljama judía de Perpiñán ${ }^{4}$. La organización de este pinqas es distinta a la del Archivo Municipal de Gerona, pues aquí se hace a partir de los bancos, su disposición dentro de la sinagoga, las personas que los ocupan y el valor de cada uno de cada uno de los asientos.

Cotejadas las dos listas resultantes de los pinqasim del Archivo Municipal de Gerona ${ }^{5}$ y del Archivo de la Corona de Aragón ${ }^{6}$, aparecen en ambas los siguientes 25 judíos:

Abram de Caslar
Astruc Sescaleta
Astruc Yossi
Benbenist Benet
Bomacip Astruc
Carcosani Semuel (Semuel
Caracosa)
Cresques Alfaquim
Cresques Duran
Duran Salamies
Haim Bofil
Içac Davi de Vilamanya
Içac Leó Astruc
Içac León
Maes[tre] León
Mordekay Grasa
Mosé Vidas
Mosé Elí
Mosé Vidal
Mosé Yossi Reuben
Mosé Levi
Vidal Leó
Yaco Astruc
Yaco Simson
Yossi Cresques de Cabanes

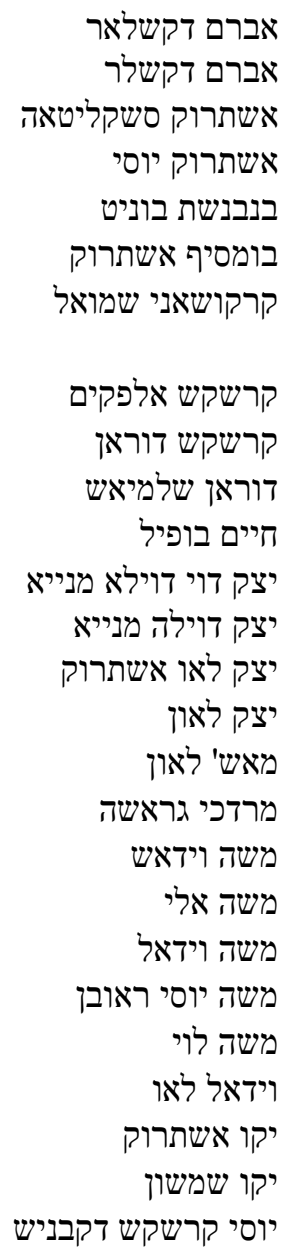

\footnotetext{
${ }^{3}$ Meritxell Blasco, "La Genizah Catalana. Relaciones entre algunos documentos hebraicos de Barcelona, Gerona y Perpiñán", Hispania Judaica Bulletin 10 (2014/5774), p. 273-285.

${ }^{4}$ Fue Jaume Riera, en aquel momento responsable del Archivo de la Corona de Aragón, quien nos avisó del hallazgo de estos fragmentos. Además, observó que en la guarda anterior del dicho protocolo se apreciaba un limpio y largo corte de escalpelo en el pergamino y la evidencia de una precipitada y traumática extracción de los papeles de relleno de la encuadernación, que después de su estudio podemos afirmar, que se trataría de los custodiados en la actualidad en el Archivo Municipal de Gerona. Véase Meritxell Blasco, "La Genizah Catalana. Relaciones entre algunos documentos hebraicos de Barcelona, Gerona y Perpiñán”. p. 275.

${ }^{5}$ En lo sucesivo AMG.

${ }^{6}$ En lo sucesivo ACA.
} 
Este hecho nos hace pensar que ambas listas fueron más o menos contemporáneas y, aunque parciales, ya que proceden de documentos muy fragmentarios, pueden servir de base para el estudio antroponímico que proponemos.

Aportamos aquí la lista total de judíos y algunas judías que aparecen en ambos documentos con el nombre que aparece en el documento, su lectura ${ }^{7}$, así como el documento donde aparece ${ }^{8}$ :

[...]de Cabanes
[En] lac Calot
[N']Enfant Semuel
Abram Asmies Cabrit ${ }^{9}$
Abram Bonafos
Abram Cohen
Abram de Bisaldun ${ }^{10}$
Abram de Caldes
Abram de Caslar ${ }^{11}$
Abram de Puiglec (?)
Abram Içac de Monbaulo
Abram Memet
Abram Sealtiel
Abram Vidal
Aser Içac
Aser Meir
Astruc de Bisaldum
Astruc de Lunel
Astruc Descortal
Astruc Haim
Astruc Leó
Astruc Maimon ${ }^{12}$
Astruc Melau
Astruc Pansaul
Astruc Semuel Bomacip
Astruc Sescaleta
Astruc Yosef ${ }^{13}$

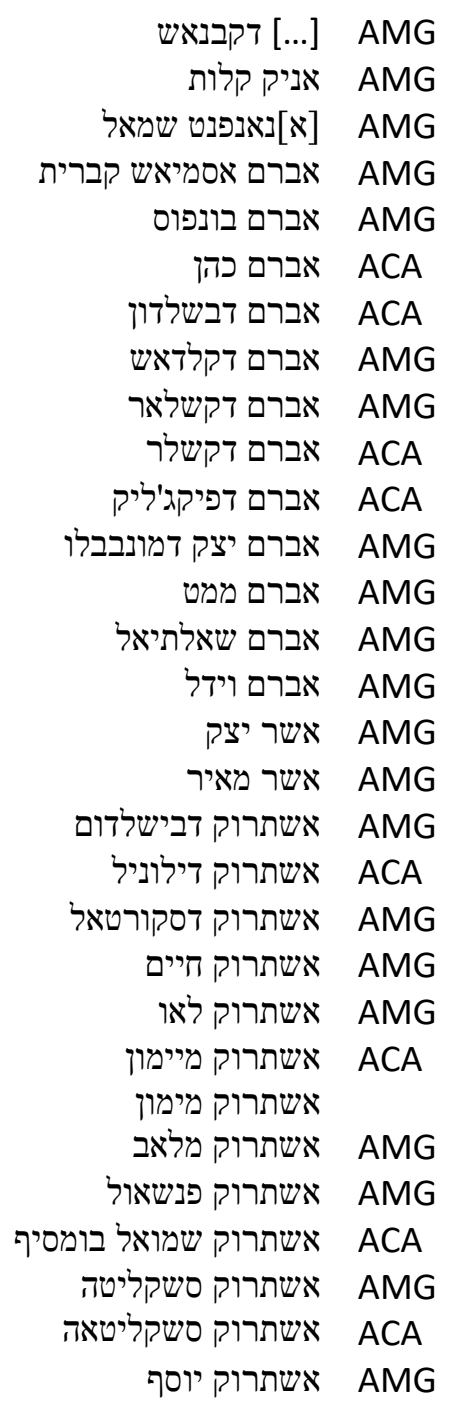

\footnotetext{
${ }^{7}$ Sigo la lectura más romanceada de los nombres hebreos del artículo de José Ramón Magdalena, vide nota 1.

${ }^{8}$ AMG. Documento del Archivo Municipal de Girona cuyo estudio está publicado por José Ramón Magdalena, vide nota 1 y ACA, documento del Archivo Corona de Aragón que publiqué en 2014, vide nota 3.

${ }^{9}$ Miembro de la aljama de Perpiñán, Fritz Baer, Die Juden in christlichen Spanien. Erster Teil. Urkunden und Regesten. Aragonien un Navarra, Berlin. 1929/1936 (en lo sucesivo Baer) no 371, (1384) p. 565-568; no 481 , (1412) p. 786 [Abram Cabrit].

${ }^{10}$ Miembro del consejo de la aljama de Perpiñán, Baer no 330 (1380), p. 487-ss [Abraam de Besaluno]; Baer no 371 (1384), p. 566.

${ }^{11}$ Judío de Besalú, Baer no 173 (1320), p. 214 [Abram de Caslar].

${ }^{12}$ Judío de la aljama de Perpiñán, Baer no 371 (1384), p. 566 [Struc Maymo].

${ }^{13}$ Judío de Puigcerdà, Baer no220 (1345), p. 305 [Astruc Jucef]
} 


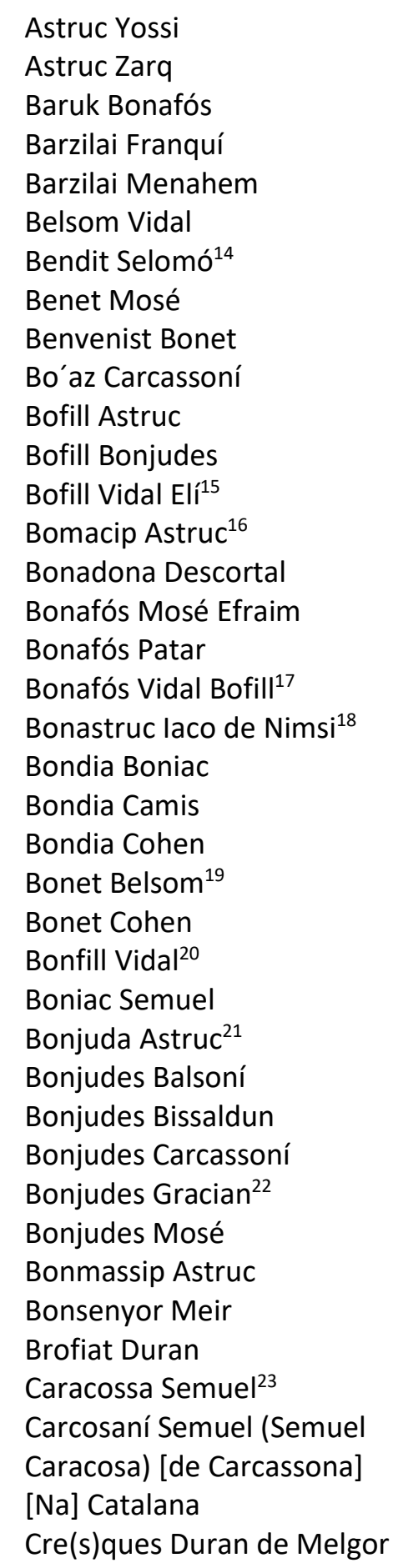

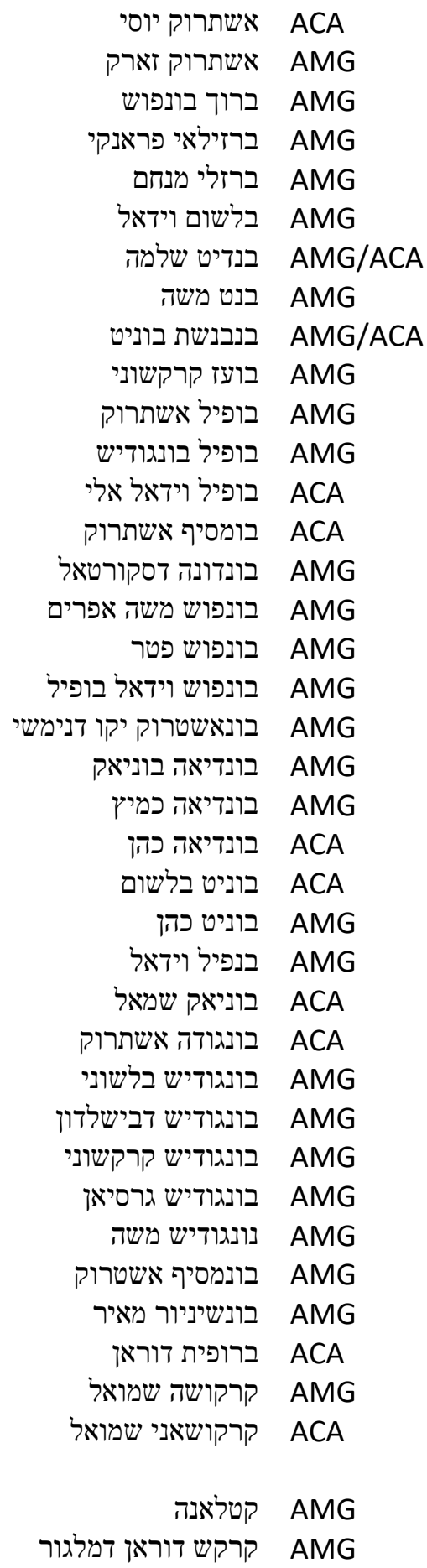

\footnotetext{
14 Miembro del consejo de la aljama de Perpiñán, Baer no 330 (1380), p. 487 [Benditus Salamo]; Baer no371 (1384), p. 566-567 [Bendit Salamo].

${ }^{15}$ Secretario de la aljama de Perpiñán, Baer no 481 (1412), p. 786.

${ }^{16}$ Miembro del consejo de la aljama de Perpiñán, Baer no 371 (1384), p. 566-567.

17 Judío de la aljama de Perpiñán, Baer no 309 (1373), p. 452 [Bonafos Vidal].

18 Judío de la aljama de Perpiñán, Baer no 481 (1412), p. 786 [Bonastruc Jacob].

${ }^{19}$ Miembro del consejo de la aljama de Perpiñán, Baer no 330 (1380), p. 487 [Bonetus Bellshom]; Baer no 371 (1384), p. 566; Baer no 439 (1392), donde aparece citado como médico (fisici).

${ }^{20}$ Miembro del consejo de la aljama de Perpiñán, Baer $n$ o481 (1412), p. 786 [Bofill Vidal].

${ }^{21}$ Miembro del consejo de la aljama de Perpiñán, Baer $n=371$ (1384), p. 566-567 [Bonjuha Struc].

22 Judío de Perpiñán, Baer no439 (1391), p. 693 [Bonjuhes Gracia]

23 Judío de la aljama de Perpiñán, Baer no 309 (1373), p. 452 [Samuel Caracosa de Perpenya].
} 


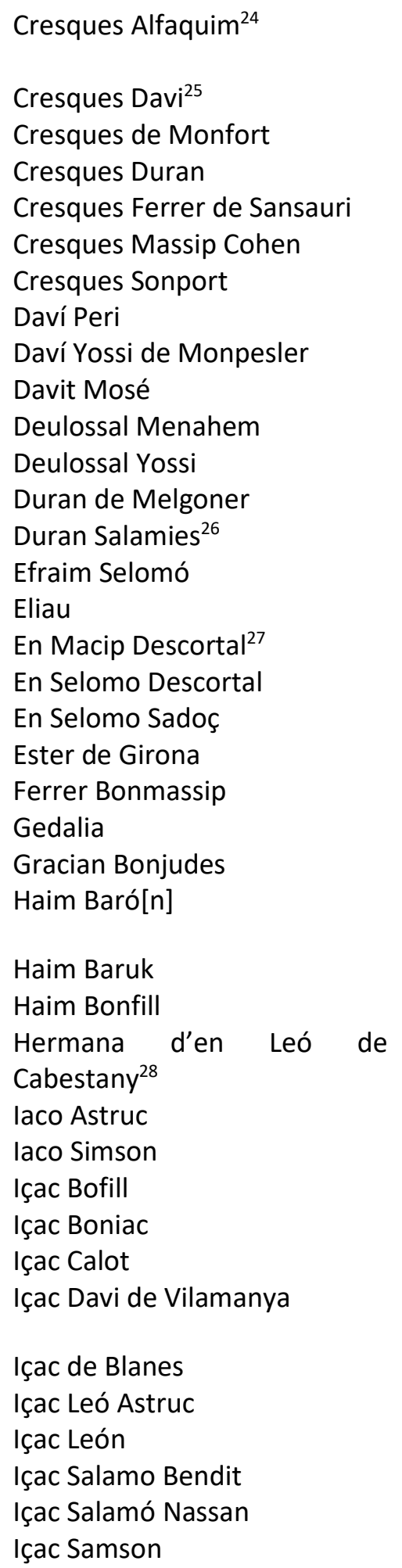

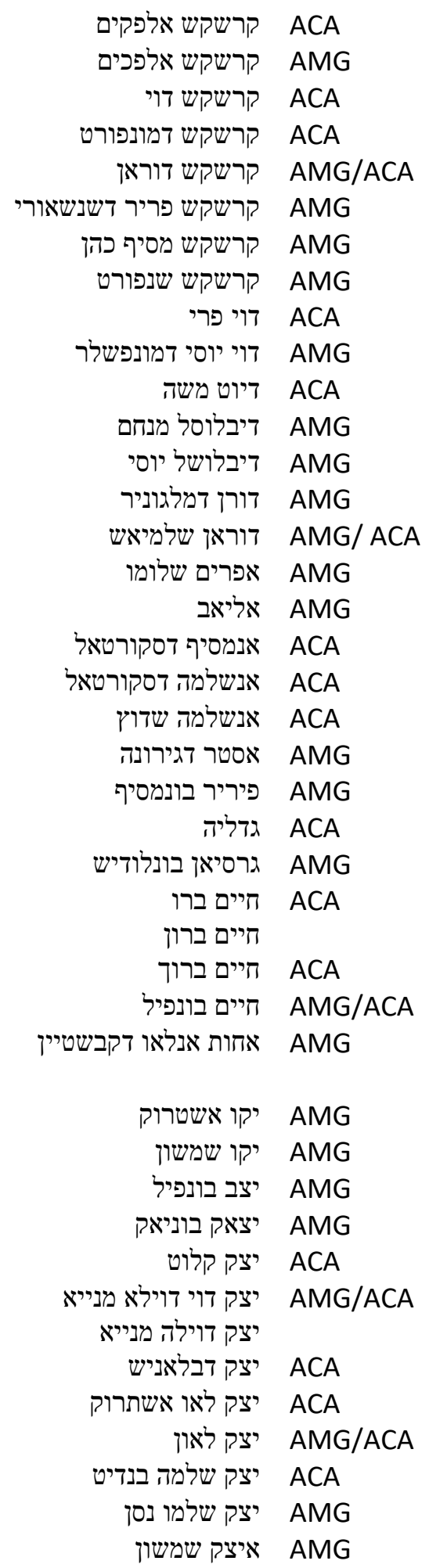

\footnotetext{
24 Miembro del consejo de la aljama de Perpiñán, Baer no 330 (1380), p. 487 [Bonanash Cresques Alfaquim]; Baer no371 (1384), p. 566-567 [Bonanash Cresques Alfaquim].

${ }^{25}$ Miembro del consejo de la aljama de Perpiñán, Baer no 330 (1380), p. 487 [Cresques Davi]; Baer no371 (1384), p. 566-567 [Cresques Davi].

${ }^{26}$ Judío de la aljama de Perpiñán, Baer no 481 (1412), p. 786 [Durand Salamies].

${ }^{27}$ Acaso miembro del consejo de la aljama de Perpiñán Baer no371 (1384), p. 566-567 [Salamo Bonsenyor dez Cortal].

${ }^{28}$ Secretario del consejo de la aljama de Perpiñán, Baer no 363 (1383), p. 555; no371, (1384), p. 566-567 [Leo de Cabastan, Leo de Capstany].
} 


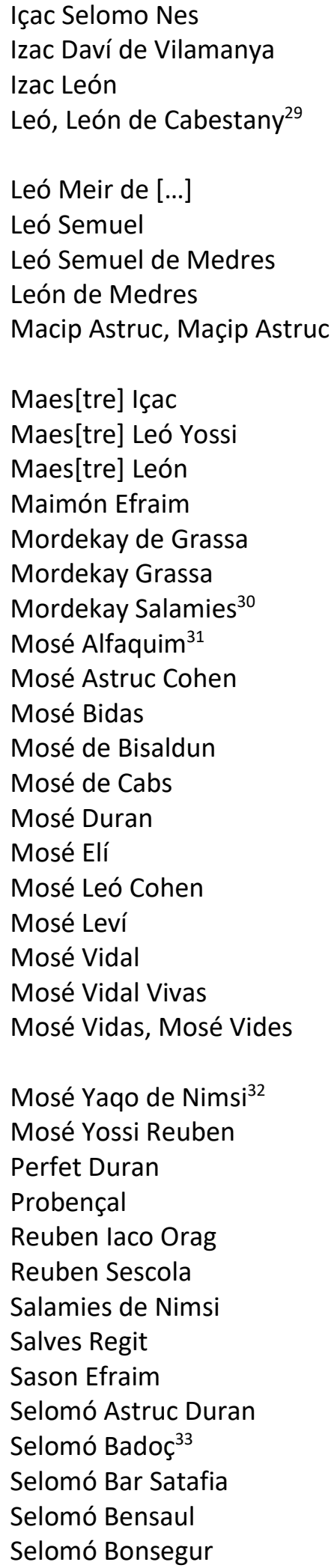

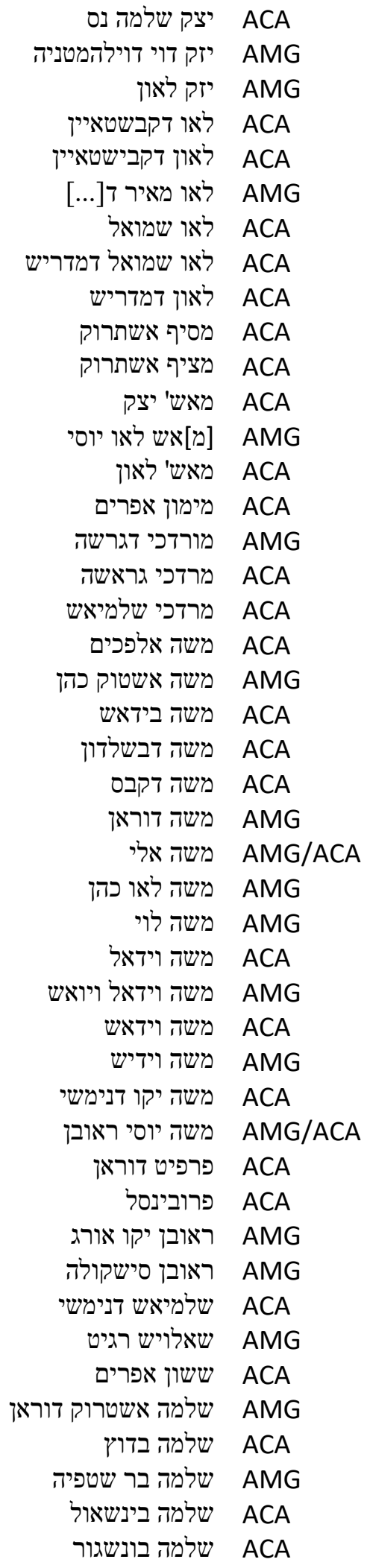

\footnotetext{
${ }^{29}$ Síndico de la aljama de Perpiñán, Baer no 363 (1391), p. 555; Baer no 371(1384), p. 566-567 [Leo de Capstany].

30 Síndico de la aljama de Perpiñán, Baer no 371 (1384), p. 566-567 [Mordohay Salamies].

${ }^{31}$ Síndico de la aljama de Perpiñán, Baer no 371 (1384), p. 566-567 [Mosse Alfaquim].

32 Judío platero de la aljama de Perpiñán, Baer no 229 (1343), p. 321.

33 Sastre de la aljama de Perpiñán, Baer no 385 (1367), p. 411-412.
} 


\begin{tabular}{|c|c|c|}
\hline Selomó Cabrit & שלמה קבריט & ACA \\
\hline Selomó Daví & 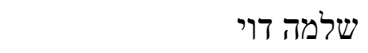 & AMG \\
\hline Selomó de Barbastre & שלומה דברבשטר][] & ACA \\
\hline Selomó de Carcasona & שלמה דקרקשונה & ACA \\
\hline Selomó de Morell & 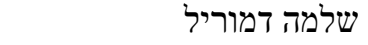 & AMG \\
\hline Selomó Descortal & שלמה דסקורטאל - של & ACA \\
\hline Selomó Ferrussol & שלמה פרשול & AMG \\
\hline Selomó Haana & שלומה חזן & AMG \\
\hline Selomó Ibn Sals & שלמה ן' שלש & AMG \\
\hline Selomó Pasat & שלמה פשאד & ACA \\
\hline Sem Tov lehudá & שם טוב יהודה & AMG \\
\hline \multirow[t]{2}{*}{ Semuel Alfaquim ${ }^{34}$} & שמואל אלפכים & ACA \\
\hline & שמואל אלפכים & AMG \\
\hline \multirow[t]{2}{*}{ Semuel Astruc Bofill } & שמואל אשתרוק בופיל & ACA \\
\hline & שמואל אשטוק בופיל & AMG \\
\hline Semuel Bendit & שמואל בנדיט & AMG \\
\hline Semuel Bomasip ${ }^{35}$ & שמואל בומסיף & ACA \\
\hline Semuel de Lunel & שמואל דלוניל & ACA \\
\hline Semuel laco de Nimsi & שמואל יקו דנימשי & AMG \\
\hline Semuel Içac & שמואל יצק & AMG \\
\hline Semuel Rimok & שמואל רימוך & AMG \\
\hline Semuel Roget & שמואל רוגיט & ACA \\
\hline Vibas Bofill & 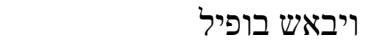 & AMG \\
\hline Vidal Astruc ${ }^{36}$ de Nimsi & וידאל אשטוק דנימשי & AMG \\
\hline Vidal Bonmarc & וידאל בונמרק & AMG \\
\hline Vidal de Coclliure & וידאל דקוקליברה & AMG \\
\hline Vidal de Vilamanya & 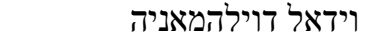 & AMG \\
\hline Vidal Elí & וידאל אלי & ACA \\
\hline Vidal Hasdai & 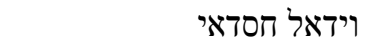 & ACA \\
\hline \multirow[t]{2}{*}{ Vidal Leó, Vidal León } & וידאל לאו & ACA \\
\hline & וידאל לאון & AMG \\
\hline Viuda de Abram de Caldes & אלמנת אברם דקלדס & AMG \\
\hline Viuda de Astruc Bonmassip & אלמנת אשטרוק בונמסיף & AMG \\
\hline Viuda de Astruc de Bissaldun & אלמנת אשטרוק זבישלדון & AMG \\
\hline Viuda de Cresques de Gàbia & אלמנת קרשקש דגביאה & AMG \\
\hline Viuda de Daví de Vilamanya & אלמנת דוי דוילהמאניה & AMG \\
\hline $\begin{array}{l}\text { Viuda de Daví Yossi de } \\
\text { Monpesler }\end{array}$ & Monpesler & AMG \\
\hline Viuda de Hasdai Tobros ${ }^{37}$ & אלמנת חסדאי טוברוס & AMG \\
\hline Viuda de Içac Abram & 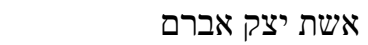 & AMG \\
\hline Viuda de Içac Albacar & אלמ' יצק אלבאקר & AMG \\
\hline Viuda de Içac Deulosal Bofill & אלמ' יצק דסלושל בופיל & AMG \\
\hline Viuda de Vidal Elí & אלמ' וידאל אלי & AMG \\
\hline
\end{tabular}

\footnotetext{
${ }^{34}$ Médico y síndico de la aljama de Perpiñán junto a Leo de Cabastany, Baer no 363 (1391), p. 555 [Samuel Alfaquim]; Baer no 459 (1395), p. 722 [Samuel Alphaquim].

${ }^{35}$ Secretario de la aljama de Perpiñán, Baer no 481 (1412), p. 786 [Samuel Bonmassip].

${ }^{36}$ Miembro del consejo de la aljama de Perpiñán, Baer no 330 (1380), p. 487 [Vitalis Sruch]; Baer no371 (1384) p. 566-567 [Vitali Struc].

37 Miembro del consejo de la aljama de Perpiñán, Baer no 330 (1380), p. 487 [Aday Tauros]; Baer no371 (1384) p. 566-567 [Aday Tauros].
} 


\author{
Viuda de Vidal Samiel ${ }^{38}$ \\ Yaco Astruc \\ Yaco Simson \\ Yom Tov Yehudá \\ Yossi Bonastruc \\ Yossi Cresques de Cabanes \\ Yossi Mosé \\ Yossi Mosé Cohen \\ Yossi Reuben \\ Yucef Cresques de Cabanes
}

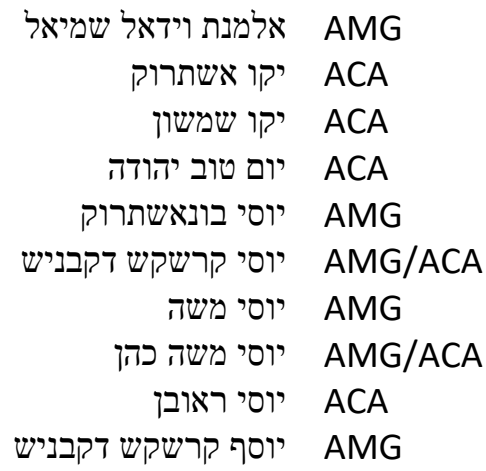

\section{Los prenombres o nombres de varón}

De los 191 nombres de varón inventariados, 87 son hebraicos, propios de la tradición bíblica:

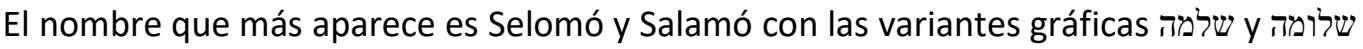

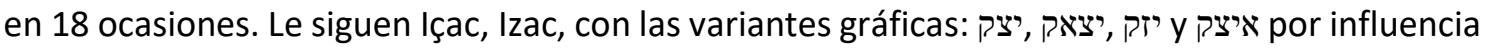
del romance vernáculo catalán y Mosé (משה Mošeh), en 13 ocasiones. Abram (אבקם) en lugar de Abraham (אברהם) por influencia del romance vernáculo y Semuel (Šĕmu'el שמואלם), en 12. Yossi (יוסי), en una ocasión Yucef (יוסף Yosef) y Daví (דוי), en una ocasión David (דיוט sic!) en lugar de David (דוד) por influencia del catalán, aparecen en 5 recurrencias. En 3 ocasiones se escriben los nombres: Yaco (יקו) en lugar ve Ya`acob (יעקב) y Haim (מרים (T) איים).

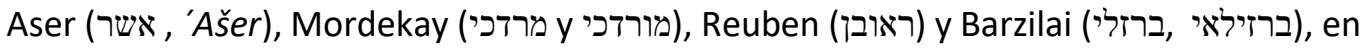
dos ocasiones.

En una única ocasión aparecen los nombres Baruk (ברוך), Bo'az (בועז), Efraim (אפרים), Hasdai (חסדאי), Gedalia (גדליה), Sason (ששון), Yom Tov (יום טוב), Sem Tov (שם (בוך) y Eliau escrito

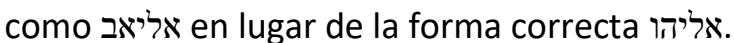

Aparece una única vez el nombre de origen árabe Maimon (מימון).

El resto de nombres que aparecen en la lista no son semíticos. Astruc (אשתרוק), nombre muy corriente entre los judíos de la antigua Corona de Aragón, deriva del latín vulgar 'astrugus', afortunado, feliz, forma que a su vez deriva del latín 'astrum', astro. Es el nombre no semítico que aparece en más ocasiones, 14. Una variante del mismo nombre aparece una única vez: Bonastruc (בונאשתרוק) formado por el catalán antiguo 'bon', bueno, más Astruc.

Otro de los nombres más frecuentes, 10 ocasiones, es Cresques (קרשקש) derivado del latín 'crescěre', crecer, aumentar. Con 9, Vidal (וידאל), del latín 'vitalis' y el catalán 'vidal'

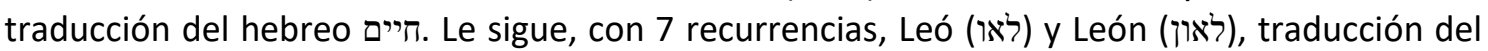
hebreo אריה. Bonjudes (בונגודיש), aparece en 6 ocasiones y Bonjuda (בונגודה) solo una, nombre derivado del catalán 'bon jueu', buen judío. Bofil o Bofill (בופיל) 'bon fill', buen hijo, aparece en 4 ocasiones. Macip (מסיף), Maçip (מציף) del catalán 'macip', joven, aprendiz, sirviente, del latín 'mancipium', aparece 3 veces y 1 su compuesto Bonmassip (בונמסיף). En 3 ocasiones también: Bonafós (בונפוש) del catalán 'bona fos', que sea bueno y Bondia (בונדיאה), tבונסי) traducción al catalán de Yom Tov (יום טוב).

Con solo 2 recurrencias aparecen los nombres de: Bendit (בנדיט), del catalán 'beneit', bendito, traducción Baruk (ברוך); Bonet (בוניט) diminutivo catalán de 'bueno'; Duran (ברוך), דיברן) דוראן) del catalán 'durant' , que persiste y Deulossal (דיבלושל ,דיבלוסל) que proviene de la forma ritual catalana 'Deu lo salvi', Dios lo salve.

Solo en 1 ocasión aparecen los nombres: Benvenist (Benvenist) acaso derivado de una forma ritual mozárabe 'tu ben venisti', bienvenido; Benet (בנט) del latín 'benedictus', bendito,

\footnotetext{
38 Médico de Perpinán y hermano de Mehir Samiel, Baer no 330 (1380), p. 488 [Vitalis Samiel]; Baer no 371 (1384), p. 566-567 [Vitalis Samuelis]; Baer no 439 (1391), p.693 [Vitalis Samiel].
} 
traducción del hebreo Baruk (ברוך); Vibas (ויבאש), variante de Vives, Vital; Boniac (בוניאק), derivado de 'bon Ya'acob'; Belsom (בלשום), tal vez derivado de la expresión en catalán 'bell hom'39; Brofiat (ברופית) quizá del catalán 'profit', provecho ${ }^{40}$; Ferrer (פיריר), del catalán 'ferrer', herrero, acaso en referencia al nombre hebreo de Barzilai ${ }^{41}$; Gracian (גרסיאן), traducción del hebreo חפופר 'gracia'; Perfet (פרפיט) del latin 'perfectum', catalán 'perfect', perfecto; Salamies (שלמיאש), formado por "שלום ; (שאלויש) y Palves Probençal (פרובינסל), el único nombre gentilicio.

En el listado aparecen 16 mujeres, una con nombre bíblico hebreo Ester, escrito erróneamente אסטר en lugar de אסתר; Bonadona (Bonadona) del catalán 'buena mujer' y una es llamada por su gentilicio, Catalana (קטלאנה). Las demás, en 12 ocasiones, reciben el nombre de viuda de... y una es llamada por el parentesco hermana de...

\section{Los apellidos o nombres de familia:}

El grupo minoritario es el formado por nombres hebraicos de la tradición Bíblica con 69 items. Muchos de ellos aparecen también como nombres en la lista anterior. Ordenados por la frecuencia en que aparecen son: Cohen (כהו) (משה), en 7 ocasiones; le siguen Mosé (שלה) Salamó o Selomó (שלמה) y Yossi (יוסי), con 5. Elí (אלי) y Semuel (שמואל) con 4. Daví (דמואי), Efraim (אפרים), Içac (יצק), Meir (מאיר), con 3. Menahem (מנחם), Reuben (ראובן), Simson (שמשון), con 2. Encontramos

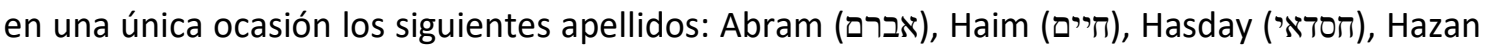

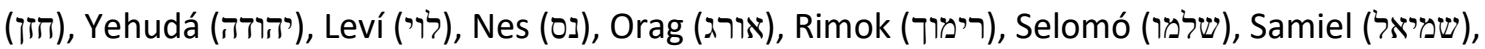
Samsón (שמשון), Sealtiel (שאלתיאל), Patar (פטר) (פרי), Pehi (יהודה), Yosef (יוסף) y Zarq (זרקל). Solo en dos ocasiones encontramos el apellido o nombre de familia a la hebrea, es decir

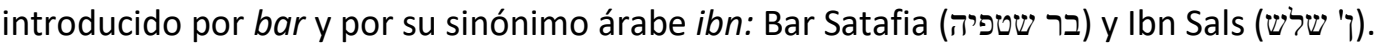

Del árabe encontramos Alfaquim (אלפכים) en 3 ocasiones y una sola vez Maimon (מלר (מלים), מלימון), מימון) y Albacar (אלבאקר).

Los apellidos de origen romance son mayoritarios con 84 ítems y como en el caso anterior pueden ser también prenombres. Ordenados por la frecuencia en que aparecen en la

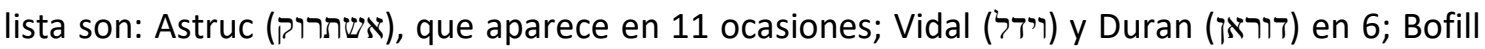
(בופיל) en 5; Bendit (בומסיף), Bונדיט), Bomacip (בונמסיף), Bonmassip (בונלודיש), Bonfil,

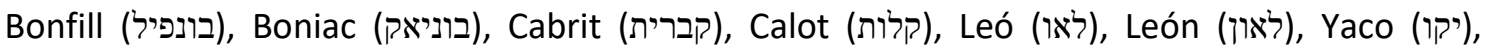
Salamies (שלמיאש) en 2; Asmies (באסמיאש), Badoç (ברוץ), Baró, Barón (ברון לרון), Belsom (בלוץ),

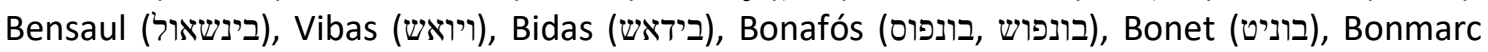

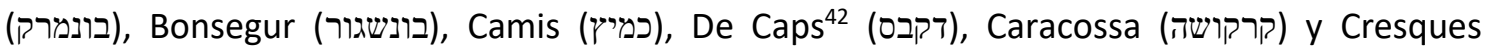
(קרשקש), de Grassa (דגרשה), Deulosal (פסרושל), (פריר), Ferrer (פרשול), Gracian (גרואל),

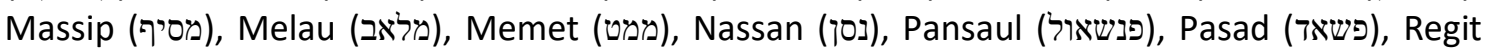

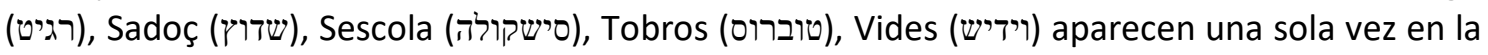
lista.

\section{Apellidos gentilicios o con topónimos}

Los topónimos que aparecen formando parte de los apellidos son:

- de Barbastre ([ברבשטר]א), en catalán Barbastre, Barbastro, ciudad de la provincia de Huesca.

- dדבישלדום ,דבשלדון), de Bisaldun latín 'Bisuldunum', 'Bisuldunun', Besalú.

- de Blanes (דבלאניש), Blanes, población de la provincia de Gerona.

- d דקבנאש), Cabannes, población de la Provenza, en el distrito de Arlés.

\footnotetext{
${ }^{39}$ Véase Robert Ignatius Burns, Jews in the Notarial Culture: Latinate Wills in Mediterranean Spain, 12501350. Berkley, University of California Press, 1996, p. 216.

${ }^{40}$ Robert Ignatius Burns, Jews in the Notarial Culture.., p. 224.

${ }^{41}$ Robert Ignatius Burns, Jews in the Notarial Culture.., p. 113.

${ }^{42}$ Acaso de la familia judía Cap de origen catalán.
} 
- de Cabestany (דקבשטיין), en occitano 'Cabestanh', actual Capestang, ciudad situada al sudeste de Perpiñan.

- d de Caldes (דקלדאש), Caldes, acaso Caldes de Montbui, en la provincia de Barcelona.

- de Carcasona (דקרקשונה), en occitano Carcassona, ciudad francesa situada en el sur de Francia, a medio camino entre Perpiñán y Toulouse.

- de Caslar (דקשלאר), acaso Castelar, alguna población cercana a Puigcerdá43.

- de Coclliure (דקוקליברה), en catalán Cotlliure, Colliure, ciudad francesa de la comarca del Rosellón.

- de Gàbia (דגביאה), sin resolver.

- de Girona (דגירונה), Gerona.

- de Lunel (דילוניל), Lunel, población del Languedoc-Rosellón, Francia,

- de Monbaulo (דמונבבלו), Montbault, población francesa situada en el departamento francés de Maine-et-Loire.

- Descortal (דסקורטאל), de Cortal, derivado de 'cortall', corral. Posiblemente se refiera a Els Cortals, pueblo de la Cerdaña francesa.

- de Medres (דמדריש), Madrés, sierra situada en el Languedoc.

- dדמלגור (דמלגוניר), Melgor, actual Melgucil, en occitano Melguelh, condado de Septimania en el sur de Francia.

- de Monfort (דמונפורט), Montfort, población situada en la Alta Provenza.

- de Monpesler (דמונפשלר), catalán Montpeller, en occitano Montpelhièr, Montpellier, ciudad francesa de la Occitania.

- de Morell (דמוריל). El topónimo Morell podría referirse a dos poblaciones: Morell, de la provincia de Tarragona o a Sant Moreil, en la región de Lemosín en Francia.

- de Nimsi (דנימשי), Nimes, ciudad del Sur de Francia.

- de Puiglec (?) (דפיקג'ליק), sin resolver.

- de Sansauri (דשנשאורי), Saint Saury, población francesa de la región Auvernia-RhoneAlpes.

- Sonport (שנפורט), Somport, puerto de montaña en el Pirineo Central.

- de Vilamanya (דוילהמטניה), Vilamanya, actual Villemagne, población francesa del Languedoc-Rosellón.

En nuestro listado aparecen también algunos gentilicios: Franquí (פראניקי), franco; Carcassoní (קרקשוני), de Carcassona y Balsoní (בלשוני).

\section{Conclusión}

Después del este análisis antroponímico de los judíos de la aljama de Perpiñán, podemos afirmar que, en líneas generales, se mantienen los mismos nombres y nombres de familia que aparecen en otros territorios de la Corona de Aragón, sobre todo Cataluña.

\footnotetext{
43 Hemos encontrado este topónimo en el testamento de Astruga, mujer de Jucef Abraham, judío de Puigcerdá, fechado en 1306. Uno de los testimonios que aparece es un tal 'Simon de Pinosa rector eclesie de Castelar'. Véase Robert Ignatius Burns, Jews in the Notarial Culture..., p. 179 del Apendix.
} 